\title{
Petawawa - the Relevant Research Forest
}

There are not many places in Canada that combine the history, scope of research, diversity of forest types and community involvement seen at the Petawawa Research Forest (PRF). The PRF is located just outside Chalk River, Ontario and has been around for nearly a century in some iteration or another. Research began in 1918 with the establishment of PSP 1 (Permanent Sample Plot 1) and since then more than 2000 projects and trials have taken place over PRF's 10000 ha.

As with many institutions that have been around as long as the PRF, its existence has not always been certain. During the mid-90s the Petawawa National Forestry Institute (as it was called) was dismantled by the Federal government but fortunately the forest was left standing. In 1996 it became the Petawawa Research Forest and since then staff, researchers, and other interested parties have worked diligently to nurture this changeling. Now, nearly twenty years later, the PRF is relevant and applicable in its own right. Through the creation of new projects and the continuation of older ones, plus connections with the Department of National Defence-Garrison Petawawa, Atomic Energy Canada Ltd, the Canadian Institute of Forestry, Algonquin College, the Friends of the Petawawa Research Forest, and the citizens of Renfrew County, the Petawawa Research Forest is crucial to an increasingly large community.

It is a working forest and the duration and extent of projects make it a living laboratory. Current research is concentrated in five categories: genetics, enhanced forest inventory (EFI), biomass, disturbances, and value and fibre characterization. Different seasons see different activities but each year sees an increase in overall effort, impact and results from the research. Over the past year work has included re-measurements and data collection on black and white spruce genetics, remote-sensing and on-the-ground correlations, and biomass harvesting.
Genetics research has been ongoing since the 1920s, covering a diversity of species from red pine to tamarack to white birch. Currently, it is the rangewide provenance testing of white spruce (known as 410-G) that is garnering the most attention. Throughout the province there are several sites of white spruce provenance trials and the Ontario Ministry of Natural Resources (OMNR) has made their re-measurement a priority. When re-measurement began, the sites in the PRF were included. The resulting data were a collaborative effort between the Canadian Forest Service (CFS) and OMNR. Such partnerships help reduce costs and improve results.

The 410-G experiment was wellestablished and replicated to ensure that it is statistically sound and to minimize bias. Information contributes to white spruce genetics database as well as studies on assisted migration and carbon sequestration. Well-established experi- ments such as this allow for future research to include them without having to start over or make alterations, making them a solid investment both in the present and for the future.

A black spruce genetic trial (358-C), under CFS researcher John Major, is a study of black spruce diallel crosses and is currently being re-measured. A diallel cross essentially sees each parent tree in the experiment mated to all of the other parent trees, creating all possible variations of offspring. This type of breeding is used to determine the genetic traits of each of the parent trees, and experiments such as these allow for improvements in planting stock and better quality fibre in future forests.

Although the majority of research spans decades, some of it is more immediate. The Advanced Forest Resource Inventory Tools (AFRIT), part of the EFI suite of projects, sees results in a shorter period of time. In 2012 the PRF was flown with a high density Light

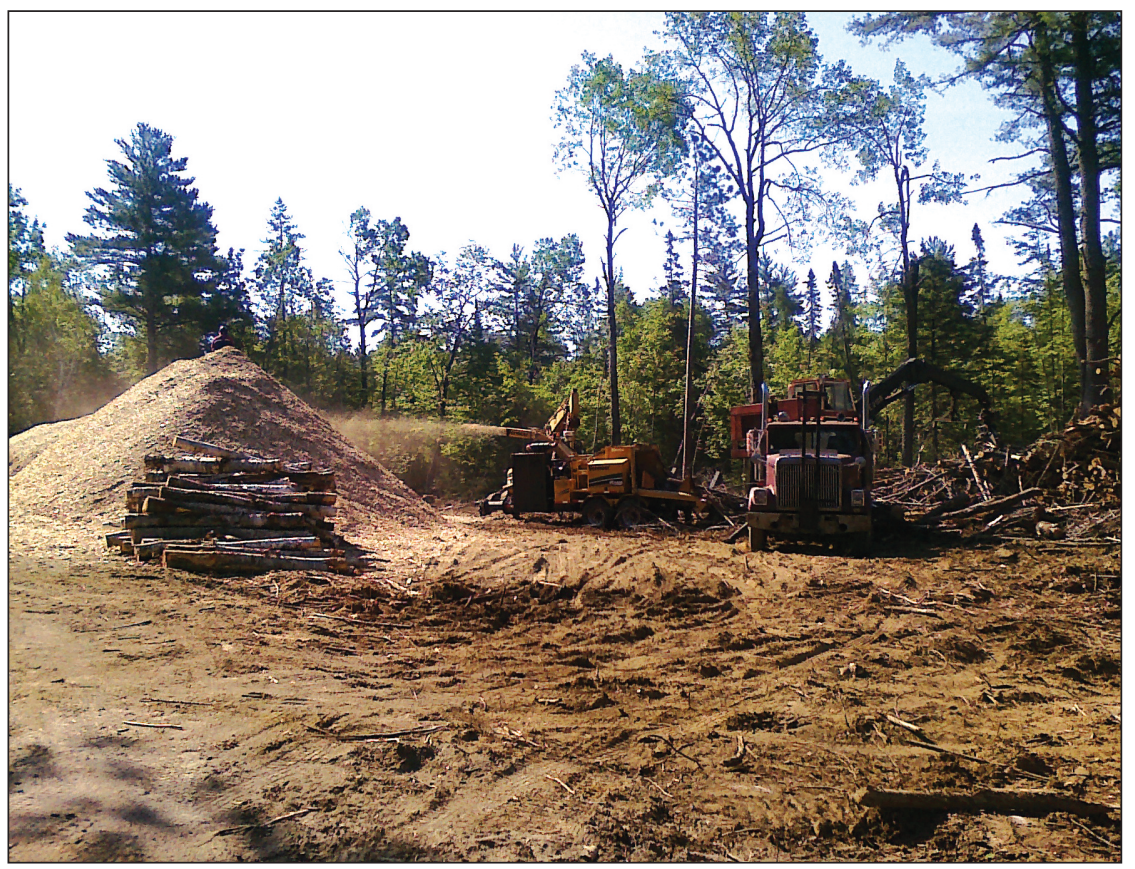

Woody biomass is chipped to be later used for bioenergy. 


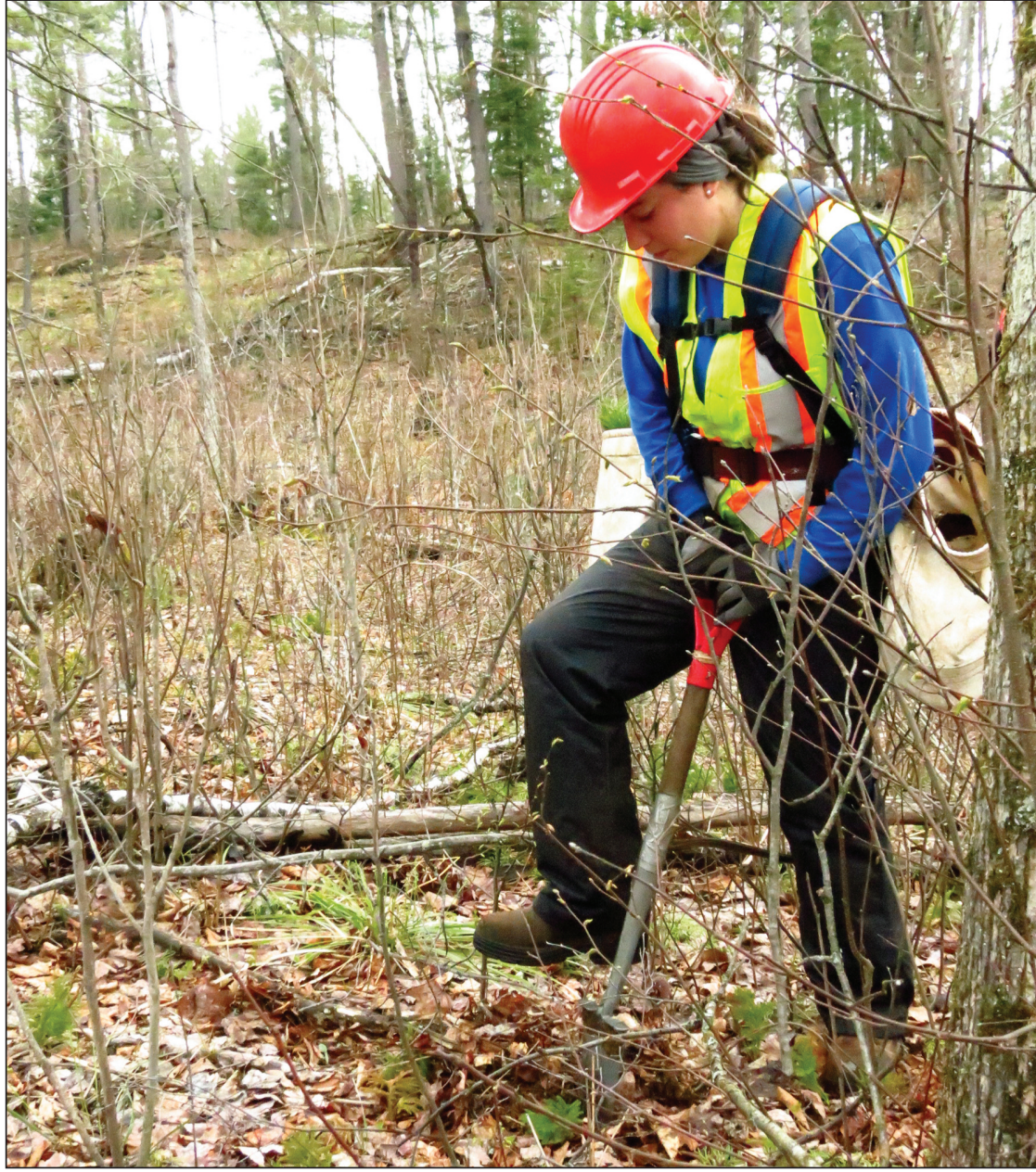

As both a working and research forest, there is constant work to be done at the PRF.

Detection and Ranging (LiDAR) sensor. AFRIT made use of this technology to produce accurate and detailed forest inventory. The sensor emits nearinfrared laser light and produces a three-dimensional point cloud of the forest (including the ground) and is attached to a fixed-wing aircraft that flies over the area to collect the data. This determines tree height, diameter and volume. Current research is to establish temporary plots to develop LiDAR relationships, explore how highdensity LiDAR might contribute to species identification, and provide PRF with an operational example of a remote-sensed inventory product. During the summer of 2013 field technicians will collect information on species, size and health to be compared to the data gathered LiDAR.

PRF is home to Canada's oldest biomass study and now also to one of the newest. The Operational Biomass
Harvest Study within the Great Lakes St-Lawrence Forest is part of a larger series of trials and the work of a partnership including federal and provincial governments, industry and academia. The objective is to look at the environmental and economic feasibility of biomass harvests to restore degraded sites to higher-valued red and white pine ecosystems. Due to a legacy of highgrading and fire prevention within the Great Lakes-St. Lawrence region of central Ontario, large tracts of pine-dominated forests have been degraded or left to succeed into low-quality, low-volume, pine mixedwoods.

With a biomass harvest, small-diameter trees, tops and branches (usually left in the bush) are pulled to the landing and chipped. These chips are used for bioenergy. Increased light levels reaching the forest floor assist in the regeneration of pine species. Researchers expect to demonstrate effi- cient supply chain and fibre flow operations, address sustainability issues, formulate policy on biomass harvesting and suggest optimal industrial uses of this material.

In order to determine the environmental and economic viability of this type of harvesting, a great amount of data has to be measured, compiled and compared. After the plot network was established, crews measured a host of environmental factors: coarse and fine woody debris, substrate and soil composition, species, health, and size. Over the winter of 2012/2013 the area was harvested using the current harvesting system (tree length) and the biomass system (whole tree) in comparable areas. During the summer of 2013 all environmental measurements are being taken again. This allows a comparison of pre- and post-harvest data that will be viewed alongside data collected over the life of the project and then paired with economic data gathered during the winter harvest. This will help to establish operational and economic efficiencies as well as environmental and energy policies for biomass utilization in Canada.

The primary focus of the PRF is forest research. However, the PRF is connected to Atomic Energy Canada, Ltd, having used a portion of AECL's land for red pine studies since the 1950s. The PRF also has partnerships with organizations outside government, including the Friends of the Petawawa Research Forest (FPRF), the Canadian Institute of Forestry and its outreach body CIFSEEK, and a variety of local groups.

The FPRF started in 2002 by a group of concerned citizens and is a registered charity with a mandate to promote and maintain the Research Forest. Volunteers do a variety of activities to promote and further the PRF, from funds for signage throughout the property to planting an arboretum on the old town site. Each year the "Friends" host or support a variety of events, including the University of Toronto Masters of Forestry Conservation field camp in the winter, the Forest Birds workshop and sugar bush activities in the spring and the Nature Walk in the fall. Many FPRF members are involved with the PRF and surrounding community and there are linkages with user groups including the Algonquin College Forestry Technician 
program, the Deep River Cross Country Ski Club, the CIF/IFC and CIFSEEK. Each year students from Algonquin College spend time in the forest learning about tree species identification and silviculture. In addition to all its roads, the PRF has a network of trails maintained by the ski club. The CIF/IFC and CIF-SEEK (previously the Forest Research Partnership) host a number of events and most tours include some time at the Research Forest. One of the greatest strengths of the PRF is that it contains a high concentration of research in an accessible and relatively small area. This is very beneficial as it allows for a greater scope of topics and information to be presented to the participants, whether they have an hour, an afternoon, or a full day.

Ultimately, it is the body of research, continued history of partnerships and collaboration, and natural beauty that make the Petawawa Research Forest one of the most relevant and irreplaceable institutions of its kind.

Loni Pierce CIF/IFC Forest Technician

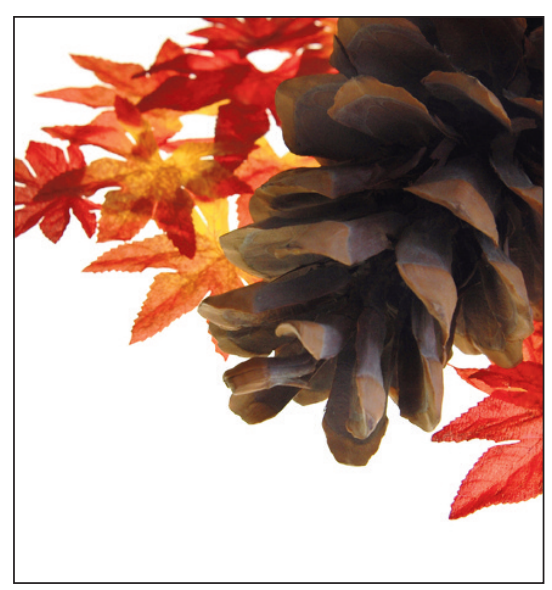

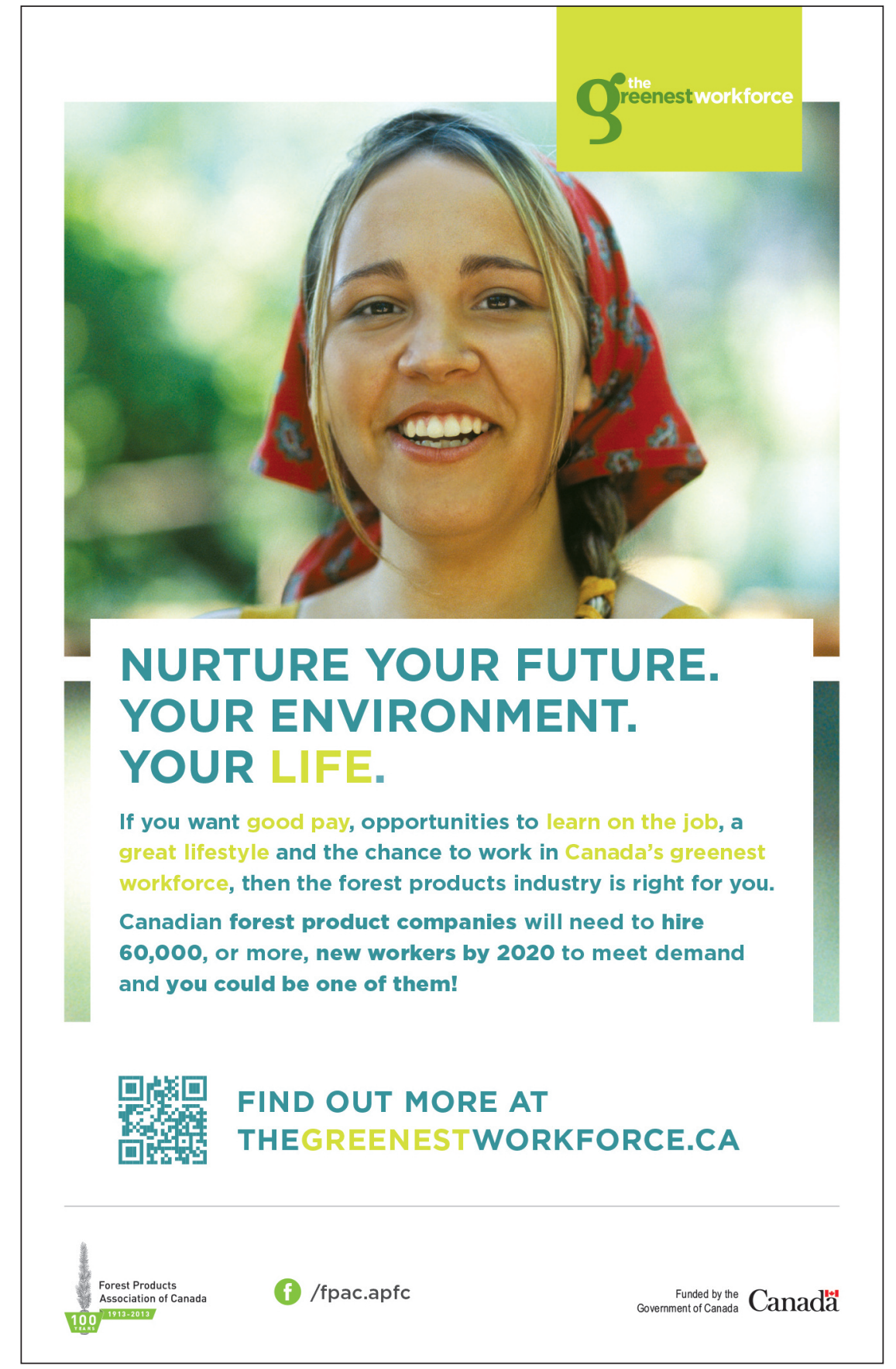

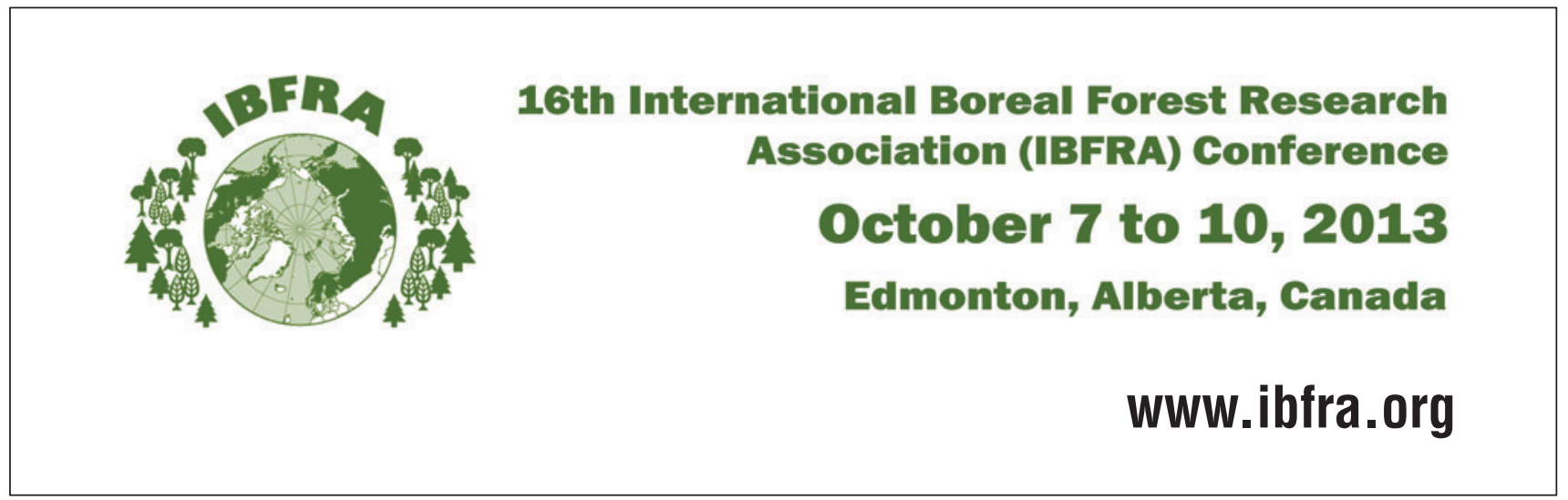

